\title{
¿JUVENTUD O JUVENTUDES? ACERCA DE COMO MIRAR Y REMIRAR A LAS JUVENTUDES DE NUESTRO CONTINENTE
}

\author{
KLAUDIO DUARTE QUAPPER ${ }^{*}$
}

\section{DE QUÉ VAMOS A HABLAR}

UNA DE LAS CARACTERÍSTICAS del proceso, múltiple y dinámico, de pensar a la juventud y a las juventudes en nuestro continente latinoamericano y caribeño, en especial durante las últimas dos décadas, es que se ha dado un cierto tránsito, desde concepciones más bien conservadoras y funcionalistas hacia versiones más integrales y progresistas respecto de este complejo mundo juvenil. Las primeras han copado por mucho tiempo no sólo las producciones de las ciencias sociales y médicas, sino que también los imaginarios colectivos con que nuestras sociedades se nutren cotidianamente. Las visiones alternativas, que han surgido muchas veces en contraposición a las anteriores, han comenzado a abrirse espacios tanto en el ámbito académico, como en el sentido común de nuestras sociedades y también en medio de quienes despliegan acciones educativas, preventivas y promocionales en el mundo juvenil de sectores empobrecidos.

Este tránsito y actual convivencia de versiones respecto de las juventudes, de los actores y sujetos juveniles, de sus producciones culturales y contraculturales, de las ofertas identitarias que los modos

* Sociólogo, educador popular en el mundo juvenil, docente universitario, cátedra «Sociología de lo juvenil». 
culturales - tanto dominantes como contraculturales - realizan, se viene dando pujado por un fuerte proceso de irrupción de este grupo social en las distintas sociedades y sus estratos en el continente. No sólo su masividad como grupo social caracteriza este proceso, sino que sobre todo la incapacidad mostrada por muchas organizaciones e instituciones sociales (públicas y privadas) de responder a las demandas y necesidades que estos grupos tienen, y también es cada vez más relevante la característica que surge desde las formas que las y los jóvenes asumen para plantear dichas necesidades y sueños, que no necesariamente es por la vía de los canales tradicionales o institucionalizados para ello, más bien se observa que están tendiendo a crear fórmulas propias de expresión de sus intereses colectivos e individuales.

En un ámbito menos estructural, vemos que son cada vez mayores las distancias y los puentes rotos que van surgiendo entre el mundo juvenil y el mundo adulto, cuestión que aflora en las familias, en las escuelas, en las comunidades locales, en las organizaciones de diverso tipo y en los propios grupos de jóvenes. Todo esto pone un matiz de dificultad en la consideración que las distintas sociedades van mostrando hacia ellos y ellas, así también se generan actitudes de tensión permanente de las y los jóvenes hacia sus entornos.

Este proceso, y el conjunto de situaciones que le caracteriza, van de la mano con los diversos lentes que se utilizan para las miradas externas e internas de lo que acontece, de sus evoluciones y manifestaciones. No es menor la ubicación de quien habla de las y los jóvenes, así como adquiere cada vez mayor importancia lo que las y los propios jóvenes dicen de sí mismos y de cómo son vistos en sus sociedades y contextos. Un desafío para las ciencias sociales surge de intentar construir miradas desde lo social que integren éstas y otras versiones en que la comunidad —incluidos los y las jóvenes - dice de sus jóvenes, de sus necesidades, sueños, estilos de vida, expresiones, agrupaciones, resistencias...

En la presente reflexión abordaremos este tránsito y actual convivencia de miradas, intentando responder la interrogante ¿es posible hablar de la juventud para referirnos a este complejo entramado social, o es necesario hablar de la existencia de las juventudes para construir miradas más integradoras y potenciadoras de lo juvenil? Las respuestas a esta pregunta van más allá de la pluralidad que asumiría el sujeto-sujeta de estudio si habláramos de las juventudes en vez de la juventud. Creemos que no está referido a una cuestión gramatical de 
número y cantidad, sino que a nuestro juicio hace mención a una cierta epistemología de lo juvenil, que exige mirar desde la diversidad a este mundo social. Junto a ello, un elemento de este tránsito es que se ha venido planteando la necesidad del reconocimiento de la heterogeneidad en el mundo juvenil, hemos dicho y se ha dicho, no es lo mismo ser joven rico que joven empobrecido, ${ }^{1}$ no es lo mismo ser mujer joven que hombre joven, etc. Pero la mención que se realiza no ha venido acompañada de la construcción de ciertas categorías analíticas que permitan mirar y remirar las juventudes de nuestro continente desde una óptica nueva y por lo tanto alternativa a la tradicional (Duarte, 1996; Kuasñosky y Szulik, 1995).

Por lo mismo se han convertido en lugares comunes, frases que se han ido vaciando de contenidos y por lo que es preciso aportar elementos en la reflexión para que demos un salto cualitativo en este aspecto y profundicemos en la reflexión: este artículo pretende contribuir en ello. Para esto, primero revisaremos las versiones más recurridas del discurso tradicional, haciendo síntesis en un segundo momento, en las trampas y dificultades que desde esta mirada se nos plantean para la construcción de miradas respetuosas del mundo juvenil. Seguidamente desplegaremos los elementos conceptuales y metodológicos que nos permitirían una mirada de nuevo tipo respecto de dicho mundo, con una sistematización de los desafíos epistemológicos que se abren a partir de esta entrada a la temática juvenil en nuestro continente, tanto para quienes viven su vida como jóvenes, como para quienes desplegamos acciones educativas y reflexivas en este mundo juvenil.

\section{2. ¡CUÁNTAS COSAS SE DICEN AL HABLAR DE LA JUVENTUD!}

Cuando en nuestras sociedades se habla de la juventud, se está haciendo referencia a varios sentidos simultáneamente. La necesaria contextualización de los discursos y acciones al respecto, y el reconocimiento de la posición de quien habla, nos permitirán una mejor comprensión de estos discursos. Una primera idea fuerza de esta reflexión es que la nominación en singular de la juventud no es tal, ya que sus significantes son diversos y refieren a varias imágenes desde

1 Pobre designa un estado, empobrecido refiere a un proceso que contextualiza e historiza su carácter de producción social (Gallardo, 1998). Entre las y los jóvenes empobrecidos consideramos sus distintas pertenencias sociales, de clase, de género, de raza, de ubicación geográfica, de pertenencia cultural, etc. 
un mismo habla con diversos hablantes. ¿Cuáles son esos diversos significados o usos que se hace de la categoría juventud?

Una primera versión, que podríamos decir es la más clásica o tradicional, y por consiguiente la que ha tenido más peso en nuestras hablas sociales, es la que define la juventud como una etapa de la vida. Dicha definición tiene al menos dos acepciones, por una parte sería una etapa distinguible de otras que se viven en el ciclo de vida humano, como la infancia, la adultez, la vejez; y por otra, es planteada como una etapa de preparación de las y los individuos para ingresar al mundo adulto.

Ambos sentidos están íntimamente ligados. En el primero de ellos, se parte desde los cambios propios de la pubertad para señalar el ingreso a un nuevo momento del desarrollo del ciclo vital, que tendría en algunos enfoques el rol de sustituir los ritos de iniciación que estarían desapareciendo desde los procesos de industrialización de nuestras sociedades. En el segundo sentido, se le otorga al primer efecto, la maduración sexual y orgánica (madurez en función de la reproducción) una connotación que se transforma en una mirada social: la madurez fisiológica sería la causa de un efecto posterior: la integración adecuada al mundo adulto. Sin embargo, esta integración al mundo adulto no es sólo consecuencia de la madurez señalada, sino de las posibilidades que cada joven tiene de participar en el mercado de la producción y del consumo. Es aquí donde esta primera versión señalada pierde consistencia, dado que trata por iguales a las y los jóvenes que ocupan diversas posiciones en el entramado social, no considerando la diversidad de situaciones que se presentan en la cotidianeidad social. La lucha entre versiones homogeneizantes y versiones que dan cuenta de la diversidad es parte de la convivencia de miradas que ya hemos señalado.

Desde esta perspectiva se ha instalado en nuestros imaginarios la versión de que el mundo joven está en un tránsito, preparándose para ser adulto, lo cual trae una serie de consecuencias que más adelante ahondaremos. Señalemos por ahora, que la moratoria psicosocial planteada por Erikson es claramente el concepto central de esta versión. Dicho concepto es el eje de la mirada clásica más conservadora y que más ha sido utilizado en los diversos discursos que las ciencias sociales y médicas vienen planteando por décadas. Entre otras debilidades de esta conceptualización, interesa mencionar la mirada de transitoriedad de la «etapa juventud», y su carácter de apresto hacia el mundo adulto. Desde esta mirada se refuerza la idea de pensar lo so- 
cial desde lo adulto, señalando lo juvenil —aquello que vive la juventud - siempre en referencia al parámetro de medida central que es lo adulto. Así lo juvenil pierde importancia en sí mismo, y siempre será evaluado en función de lo que el mundo adulto ha parametrado como lo que debe ser. ${ }^{2}$ Una segunda versión, dice la juventud para referirse a un grupo social que puede ser clasificable a partir de algunos parámetros, en especial el etáreo. Dicha variable, la edad, permitiría construir un grupo dentro de las sociedades, a los que se denomina los (y las) jóvenes. En esta versión, se tiende a confundir lo netamente demográfico, un grupo de cierta edad en una sociedad, con un fenómeno sociocultural que es lo juvenil como momento de la vida o como actitud de vida, etc.

Es importante considerar la versión de Bourdieu, quien señala que el uso de la edad para significar una compleja realidad social es una manipulación que efectúan sociólogos y otros cientistas sociales. Para este autor, «la juventud y la vejez no están dadas, sino que se construyen socialmente entre jóvenes y viejos. (...) La edad es un dato manipulado y manipulable, muestra que el hecho de hablar de los jóvenes como una unidad social, de un grupo constituido, que posee intereses comunes, y referir estos intereses a una edad definida biológicamente, constituye en sí una manipulación evidente» (Bourdieu, 1990). Vale decir, la manipulación ha sido la característica de este mal uso de la edad y de los rangos etáreos. En primer término porque desde ello se ha pretendido construir realidad, se asignan conductas o responsabilidades esperadas según edades, nuevamente sin considerar las especificidades y contextos del grupo social del que se habla. En segundo término la definición de los rangos ha estado mediada por dichas condiciones sociales, sólo que ello no se enuncia. En este sentido es interesante mirar lo ocurrido en Chile cuando asume el primer gobierno civil post-dictadura militar en el año 1990, en que el rango etáreo asumido para hablar de jóvenes desde la política social, se au-

2 En este texto, la juventud o más adelante las juventudes refieren al grupo social que puede ser categorizado desde distintas variables (demográficas, económicas, culturales, etc.); lo juvenil hace referencia a las producciones culturales y contraculturales que estos grupos sociales despliegan o inhiben en su cotidianeidad; las y los jóvenes hace referencia a los sujetos específicos en su individualidad y en sus relaciones colectivas; la juvenilización es la expresión que adquiere el proceso por medio del cual se construyen imaginarios sociales con modelos de ser joven que circulan en nuestras sociedades. 
mentó desde los 15 a 24 años, que se usaba desde más de dos décadas, hasta los 29 años como margen superior. La explicación tiene que ver con la cobertura interesada de desplegar en el marco de la denominada «deuda social» que se tendría con las y los jóvenes chilenos empobrecidos que sufrieron exclusión social durante la dictadura militar. Sin embargo, esta variación intencionada, no se hace cargo de «la realidad que construye», en tanto quien en 1990 tenía 24 años, se encontró con la posibilidad de vivir una ampliación de su «etapa como joven» al tener cinco años más, mientras se prepara para ser adulto. Es necesario señalar que dicha ampliación ha tenido efectos en el imaginario social que ya no concibe a sus jóvenes hasta los 24 años sino que les ha otorgado también esta ampliación decretada desde el Estado chileno.

La tercera versión utilizada para referirse a la juventud, dice relación con un cierto conjunto de actitudes ante la vida. Por ejemplo, se habla de la juventud para decir un estado mental y de salud vital y alegre; se usa también para referirse a un espíritu emprendedor y jovial; también se recurre a ello para hablar de lo que tiene porvenir y futuro; en otras ocasiones se le utiliza para designar aquello que es novedoso y actual, lo moderno es joven... Dichas actitudes son mayormente definidas desde el mundo adulto, a partir de una matriz adultocéntrica de comprender y comprenderse en el mundo y en las relaciones sociales que en él se dan. Visto así, el mundo adulto se concibe a sí mismo y es visto por su entorno como las y los responsables de formar y preparar a las "generaciones futuras» para su adecuado desempeño de funciones en el mundo adulto, vale decir: como trabajadores, ciudadanos, jefes de familia, consumidores, etc.

Esta responsabilidad asignada por siglos y auto impuesta a la vez, es la que va enmarcando el estilo de relaciones que entre el mundo adulto y el mundo joven se van dando. Ella, entre otras prefiguraciones, va anteponiéndose a las relaciones que se puedan generar por medio de roles, respetos implícitos, etc. De esta forma vemos que por ejemplo en la escuela secundaria, la queja de las y los estudiantes es que sus docentes se relacionan con ellas y ellos en cuanto estudiantes y no en cuanto personas jóvenes. El adulto se posiciona en su rol de profesor-profesora y pierde también la posibilidad de aprehender del joven que tiene enfrente, sin llegar a plantearse la posibilidad de juntos construir comunidad.

Mirado con este lente, en esta tercera versión, vemos que el mundo adulto tiende a acentuar sus miradas sobre el mundo juvenil (al que recordemos denomina la juventud), mayormente desde imágenes 
prefiguradas que no siempre coinciden con la realidad y por lo demás muchas veces ni siquiera logran conocer dicha realidad juvenil, ya que inmediatamente le anteponen el prejuicio que su lente les entrega. El mundo adulto mira con este lente a las y los jóvenes a partir del aprendizaje que impone la socialización adultocéntrica en que nuestras culturas se desenvuelven. Al mismo tiempo, muchos jóvenes internalizan estas imágenes y discursos, por lo que encontramos experiencias individuales y colectivas en que su despliegue cotidiano está guiado por tratar de dar cuenta de dichas situaciones: «ser como dicen que somos».

Un ejemplo de esto último, lo constituye la distinción que algunos raperos de la zona sur de Santiago hacen respecto de lo que denominan «la vieja escuela» y «la nueva escuela» del rap. Se trataría de dos generaciones distinguibles por el contenido de su música y por sus motivaciones para ser raperos. La vieja escuela elaboraría canciones signadas por temas de crítica social de corte sistémico y con propuestas de ciertas alternativas a las situaciones de dolor social; mientras tanto, la nueva escuela se caracterizaría porque son raperos de menor edad, que han surgido como tales en los últimos cuatro o cinco años, y que sus contenidos están más vinculados a la violencia y con poca crítica social. De la misma manera estos últimos asumirían como parte de su identidad el uso de la violencia y las peleas callejeras como forma de relacionarse en sus entornos. La explicación que ellos y ellas tienen para este fenómeno, es que las y los raperos de la nueva escuela estarían respondiendo al discurso criminalizador que la sociedad ha venido imponiendo en torno al ser rapero, su estética y su identidad. Vale decir, estos jóvenes se estarían haciendo cargo de un discurso dominante que los inculpa, pero que les va haciendo sentido en tanto les permitiría una cierta visibilidad social.

Una cuarta versión, que surge de la anterior, es la que plantea a la juventud como la generación futura, es decir como aquellos y aquellas que más adelante asumirán los roles adultos que la sociedad necesita para continuar su reproducción sin fin. Esta versión tiende a instalar preferentemente los aspectos normativos esperados de las y los jóvenes en tanto individuos en preparación para el futuro. Así, surge un juego entre los hablas que reconocen aspectos «positivos de la juventud» y aquellos que en el mismo movimiento refuerzan la tendencia deshistorizadora de los actores jóvenes. Por ejemplo, una forma de descalificar los aportes que las y los jóvenes realizan en distintos espacios sociales es plantear que se trata sólo de sueños y que 
ya los dejarán de lado, cuando maduren y efectivamente se vuelvan realistas como «todo un adulto». El reconocimiento de que la juventud (la etapa de la vida) sería el momento de los ideales, tiene esta doble connotación, se pretende reconocedora de los posibles aportes juveniles, pero en el mismo movimiento se les descalifica por falta de realismo y por ser pasajeros.

De la misma manera, lo que se refiere a las críticas y propuestas que realizan jóvenes y sus grupos a las formas de vida de sus sociedades, sus modos contraculturales de generar agrupamientos, de relacionarse, de comunicarse, de vestirse... son vistos como acciones de rebeldía y de no-adaptación social, en tanto no dan cuenta de lo que se espera: la subordinación de las y los jóvenes a lo que cada generación adulta les ofrece en el tiempo que les corresponde vivir. He aquí una franca lucha de poder, entre quienes ofrecen modelos a los cuales adaptarse y quienes intentan producirse y reproducirse desde parámetros propios que las más de las veces contradicen la oferta mencionada.

Otra forma de desalojar-deshistorizar a las y los jóvenes es planteando que la juventud es el momento de la vida en que se puede probar. Desde ahí surge un discurso permisivo «la edad de la irresponsabilidad» y también un discurso represivo que intenta mantener a las y los jóvenes dentro de los márgenes impuestos. Se puede probar, pero sin salirse de los límites socialmente impuestos. El hedonismo en algunos autores sería la característica de la juventud lo que la situaría en este marco de la irresponsabilidad, de la búsqueda del placer fácil, de la disposición a vivir sólo el presente...

Hasta aquí estas versiones. No son las únicas, son una muestra de lo que más aparece en el sentido común que día a día se va alimentando de discursos científicos, periodísticos, comunicacionales, religiosos, políticos, de la calle, del café, de la música, de la publicidad... Muestran una variedad de modos de concebir, hablar y representar a la juventud, que entre más nos sumergimos en el análisis más aparece como desbordando esta forma de referencia. Al parecer, la categoría usada, no logra contener el complejo entramado social del cual desea dar cuenta.

\section{CUIDADO CON LAS TRAMPAS PARA COMPRENDER}




\section{Y AUTOCOMPRENDERSE EN EL MODO DE VIDA JUVENIL}

En este momento intentaremos una síntesis en torno a las racionalidades que subyacen a las diversas versiones ya planteadas. Dichas racionalidades actúan como contenedoras de una matriz cultural que sustenta estas miradas y discursos en torno a la existencia de la juventud. Dicha matriz da cuenta de una construcción sociocultural que sitúa a este grupo social, sus producciones y reproducciones como carentes, peligrosas, e incluso les invisibiliza sacándolos de las situaciones presentes y los resitúa en el futuro inexistente. Esta matriz la hemos denominado adultocentrismo (Duarte, 1994), en tanto sitúa lo adulto como punto de referencia para el mundo juvenil, en función del deber ser, de lo que debe hacerse para ser considerado en la sociedad (madurez, responsabilidad, integración al mercado de consumo y de producción, reproducción de la familia, participación cívica, etc.).

De esta manera, cuando se significa al mundo joven en nuestras sociedades la mayor de las veces se hace desde esta matriz cuyo surgimiento en la historia va de la mano con el patriarcado. Vale decir, se construye un sistema de relaciones sociales, una cierta concepción de la orgánica social desde la asimetría [adulto+/joven-]. Esta postura no pretende crucificar a quienes se perciben o son percibidos como adultos, sino que busca desnudar una corriente de pensamiento y acción social que discrimina y rechaza aquellas formas propiamente juveniles de vivir la vida.

Al menos cuatro trampas nos presenta esta forma adultocentrista de concebir lo social y en particular a la juventud dentro de ello. Una primera concepción es la universalización como homogenización: «son todos iguales», vale decir no se elabora ningún nivel de distinciones entre los tipos de jóvenes, ni entre géneros, razas, clases sociales, estilos (contra) culturales, etc. De esta forma existe sólo una juventud, singular y total al mismo tiempo. Esta objetivación de corte positivista intenta igualarles en un concepto, se niega la existencia de las otras versiones que ya señalamos y que abren un abanico amplio de significaciones. A nuestro juicio, la juventud, si existiera, no posee carácter universal, constituye un referente conceptual que precisa de contextualización y especificidad desde sus acepciones más básicas: momento de la vida, grupo social, estado de ánimo, estilo de vida, entre otras. El reconocimiento de la heterogeneidad, la diversidad y la pluralidad, como veremos, son ejes para una nueva mirada de las juventudes en nuestro continente. 
La segunda trampa de las versiones tradicionales refiere a la permanente estigmatización que se hace del grupo social juventud y de sus prácticas y discursos, como objetivación invisibilizadora: «son un problema para la sociedad». La relación que las distintas sociedades construyen con sus jóvenes o con su juventud, se funda básicamente desde los prejuicios y los estereotipos. No se logran vínculos humanizadores, sino que se dan mayormente desde las preimágenes, desde las apariencias y desde las miradas preconcebidas por otras y otros. Se tiende a patologizar a la juventud, no se reconocen sus capacidades de aporte y de esta forma se le saca de la historia, se les sitúa como no aporte y como una permanente tensión para el orden, el progreso y la paz social. Estas imágenes son las que permiten al imaginario dominante argumentar con fuerza todas sus desconfianzas, temores y represiones contra la juventud, sus expresiones discursivas o accionales.

En este sentido se ha construido todo el conjunto de normas y deberes que debieran asumir quienes pertenecen a la juventud para cumplir en buena forma su rol actual, dado que esto tiende a no suceder, aparece una objetivación sancionadora que les responsabiliza de todos los males sociales existentes y les acusa de disfuncionales «al sistema». En el mismo movimiento, estas versiones circulantes en la cotidianeidad, tanto en el espacio de la intimidad cara a cara como en el de la masividad estructural, realizan el ejercicio de resituar a las y los jóvenes, o si se quiere a la juventud, pero condicionada a cumplir con cierta norma esperada socialmente en tanto muestran capacidad de cumplir lo esperado. Como veremos, el necesario reconocimiento de los diversos aportes juveniles y de su existencia concreta en tiempo presente, son condición de las posibilidades de construcción de sociedades fraternas y justas.

La tercera trampa consiste en la parcialización de la complejidad social como mecanicismo reflexivo. La división etapista del ciclo vital responde a una visión instalada con fuerza en los imaginarios sociales en nuestras sociedades latinoamericanas y caribeñas. Se plantea que se es joven o se es adulto (o se es infante o anciano, etc.), negando la posibilidad de convivencias o simultaneidades en la posición que se asume socialmente, es decir ser niño-niña, joven, adulto... en un mismo movimiento sin fin. Junto a ello, desde la lógica del mundo adulto de auto constituirse como quienes deben preparar a las «futuras generaciones» para la adecuada conducción de las sociedades venideras, se asume el rol de normadores-formadores de quienes asumirían 
mañana los destinos de la patria.

Así, las visiones son desde la funcionalidad del joven en tanto futuro adulto, vale decir futuro responsable y sostenedor de lo que suceda en su sociedad. Esta lógica imperante tiende a rigidizar las visiones y versiones sobre la juventud y su existencia en el ciclo vital $\mathrm{y}$ en la cotidianeidad de cada grupo social. Como veremos, las posibilidades de reconstruir una nueva mirada en torno a las nociones del tiempo (de lineal a espiral ascendente), desde las lógicas más occidentalizadas hacia aquellas que recuperan las nociones de los pueblos originarios de nuestro continente, puede ser una clave epistemológica que nos ayudaría a superar dicha rigidez en la mirada...

La cuarta y última trampa que queremos revisar, dice relación con la idealización de la juventud como objetivación esencialista: «son los salvadores del mundo». Vale decir, se les endosa una responsabilidad como los portadores de las esperanzas del cambio y la transformación de las distintas esferas de la sociedad, por el sólo hecho de ser jóvenes. Su carácter intrínseco sería ser críticos e innovadores. Esta versión del imaginario está muy difundida incluso en aquellas organizaciones e instituciones sociales de corte progresista, que por largo tiempo han buscado y en algunos casos avanzado en la construcción de sociedades justas y solidarias. Muchas veces se llega incluso a la objetivación mesiánica de plantear que «todo lo juvenil es bueno». Si bien la mayor de las veces, las y los jóvenes se encuentran en situaciones de conflicto social que les provocan dolores sociales, aunque nos ubiquemos en una lectura que intenta mirar desde las potencialidades y capacidades del mundo juvenil, ello no justifica caer en la trampa que estamos enunciando.

Estas distintas trampas a que hemos aludido, se comprenden en una mirada crítica respecto de la construcción discursiva y accional que por décadas se ha venido haciendo respecto de la juventud. Se ha asentado con fuerza la certeza de la existencia de una sola juventud que pretende englobar lo que aquí hemos mostrado como un complejo entramado social, imposible de significar con un concepto que asume múltiples sentidos. Lo que se ha dado es un proceso dominante de establecer una mirada sobre este grupo social y sus construcciones sociales en la historia, desde un lente que la observó como una unidad indivisible, uniforme e invariable. Este lente dominante por largo tiempo es el que sostiene que existe una sola juventud. Desde esta reflexión planteamos que esta juventud no existe y nunca ha existido como tal, sino sólo en la construcción que hace quien mira y en la 
versión que desde ahí se produce. La juventud es un constructo intencionado, manipulable y manipulado, que no consigue dar cuenta de un conjunto de aspectos que requieren una mirada integradora y profunda respecto de esta complejidad.

Lo que existen y que han venido ganando presencia son las juventudes, vale decir diversas expresiones y significaciones del entramado complejo que surge en nuestras sociedades desde un grupo social y que se expresa de maneras múltiples y plurales. Estas juventudes son de larga data, ${ }^{3}$ surgen como grupos sociales diferenciados, con particularidades y especificidades en cada sociedad y en cada intersticio de ella, entre los espacios de las palabras van surgiendo con distintos rostros, olores, sabores, voces, sueños, dolores, esperanzas.

Desde hace décadas se viene planteando la necesidad de agudizar la mirada, de reconstruir nuevos paradigmas, de remirar lo que hasta ahora siempre se vio de una sola forma. Si se la ha construido desde la homogenización, la estigmatización, la parcialización y la idealización, entre otras trampas, es posible plantearse el desafío epistemológico de construirlas desde otros parámetros que humanicen a quienes viven su vida como jóvenes. En el siguiente apartado, relevaremos aquellos aspectos más significativos de este proceso que se viene dando en nuestras sociedades.

\section{VOLVER A MIRAR(SE), PARA APREHENDER(SE) Y COMPRENDER(SE) ENTRE LAS JUVENTUDES DEL CONTINENTE. PISTAS PARA NUEVAS MIRADAS DE LAS JUVENTUDES}

Estamos en el camino del tránsito y de la convivencia ya anunciada. En el esquema de Kühn se trataría de un período de anomalía en que se ha salido al camino de las conceptualizaciones tradicionales, intentando instalar en la reflexión otros elementos no considerados hasta ahora para mirar, aprehender y comprender a las juventudes en nuestras sociedades. Para ello señalaremos algunas pistas de corte epistemológico, que nos entreguen herramientas para este ejercicio de conocimiento que cotidianamente realizamos respecto de las y

3 No siempre han tenido presencia histórica, en nuestro continente surgen de la mano del cambio del modo de producción hacia el establecimiento del modo capitalista industrializado y del fortalecimiento de la escuela y la universidad en los distintos sectores y clases sociales. Por ello en cada región y/o país tendrán una data de irrupción histórica diferente (Muñoz, 1999). 
los jóvenes. Dichas pistas tienen ese carácter en tanto no pretenden instituir leyes ni modelos que circunscriben acciones, sino matrices analíticas que generen nuevas formas de acercamiento al sujeto-actor joven, sus grupos, sus expresiones, sus discursos, etc. Se trata entonces de sistematizar un conjunto de caminos que permiten ponerse en condiciones de pensar y construir relaciones con el mundo juvenil y su amplia gama de colores.

Una primera pista refiere a la necesidad de aprehender a mirar y conocer las juventudes, en tanto portadoras de diferencias y singularidades que construyen su pluralidad y diversidad en los distintos espacios sociales. A las ya tradicionales exigencias respecto de la clase, el género, la religión y la raza, se suman hoy exigencias respecto de los estilos culturales y de los subgrupos etáreos que se comprenden dentro del grupo social juventud. Si bien hemos criticado la versión etárea que construye una juventud sin recoger diferencias y hace depender de un dato demográfico la construcción de realidades sociales, vemos que en el acercamiento a las y los jóvenes es necesario distinguir los subgrupos que se dan, si se trata de manifestaciones sociales entre los 15 y 17 años, en que seguramente estudiarán en secundaria o por lo menos estarán en situación de hacerlo, que si se tratara de grupos entre 26 y 29 años los que posiblemente estén planteándose cuestiones relativas a la construcción de familia y la inserción laboral. No estamos usando la edad como un dato que construye realidad a priori, sino que la usamos como referente de categorización, que no explica las situaciones que se dan entre las diversas juventudes, y que exige dinamismo en su uso. ${ }^{4}$

De la misma manera, la pertenencia a uno u otro estilo cultural implica en el mundo juvenil asumir cierta estética de presentación y representación en el espacio. Por ello, provoca identidad pertenecer a un grupo rap, que diferenciará de pertenecer a un grupo de rockeros metálicos. Esta diferenciación, por oposición o por semejanzas entre uno y otro grupo de jóvenes, entre sus estilos (contra) culturales, les permite construirse una posición en el mundo, les da la posibilidad de atribuir sentidos desde dicha posición y a la vez situarse ante ellos y ellas mismas y ante los y las demás con una cierta identidad. La músi-

$4 \quad$ No sólo respecto de las juventudes es esta consideración, sino que respecto de los distintos grupos sociales a los que se les exige ciertas conductas atribuidas la posesión de cierta edad biológica, por sobre su edad social, es decir cuál es la representación que de su pertenencia etárea se hace en el contexto específico de su sociedad. 
ca, el fútbol, el graffiti, la batucada, la ropa, el pelo, la vestimenta, entre otros aspectos íntimos y públicos, son los espacios e insumos que les permiten materializar dichas opciones. Reconocer estas distinciones que producen diferencias -y lamentablemente en ocasiones también desigualdades - es clave de lectura para recoger la diversidad de las juventudes de nuestro continente.

Esta diversidad, que en algunos casos produce un relativismo que niega precisión al análisis social, plantea el desafío de reconocer la complejidad a que hemos aludido, pero al mismo tiempo, invita a desplegar la capacidad de precisar y relevar los aspectos vitales para la comprensión de aquello que se muestra como complejo. En ese sentido es que surge la segunda pista a considerar, que dice relación con la necesidad de desplegar miradas caleidoscópicas hacia o desde el mundo juvenil, que permitan recoger la riqueza de la pluralidad ya mencionada. Se trata sin duda de un esfuerzo, por dejar de lado el telescopio, aquel instrumento que permite imágenes fijas y desde la lejanía, para comenzar a usar el caleidoscopio, aquel juguete que nos permite miradas múltiples, diversas, ricas en colores y formas a cada giro de contraluz que efectuamos.

Para capturar la complejidad de las juventudes en nuestras sociedades es vital la realización cada vez más profunda y precisa de este ejercicio de mirar caleidoscópicamente sus mundos, sus vidas, sus sueños.

Vinculado a lo anterior surge una tercera pista, que tiene relación con dejar de lado el telescopio usado para mirar lo juvenil. Por largo tiempo las miradas predominantes son desde la lejanía, desde el escritorio de la oficina pública, la ONG, la academia, la Iglesia, etc. Se requiere en este nuevo esfuerzo epistemológico salir a la calle, vincularse con las y los jóvenes, oír sus hablas, mirar sus acciones, sentir sus aromas. Este acercamiento es hoy día más posible de realizar, en tanto las metodologías investigativas abren caminos de encuentro entre lo cuantitativo y lo cualitativo, en especial esta última, ofrece variantes riquísimas para aprehender y comprender los mundos juveniles. La permanente consideración de los contextos específicos y globales, la necesaria historización de las experiencias juveniles, la referencia a la pertenencia generacional que cada grupo despliega, son algunos de las claves que surgen en esta pista que propone la vinculación directa e íntima con el mundo juvenil, múltiple y plural, como condición de la generación de conocimiento comprensivo en nuestro continente. No se trata de una dependencia y pérdida de autonomía de 
quienes conocen o investigan, sino que se busca la generación de diálogos permanentes entre los diversos mundos sociales, entre ellos el de las y los jóvenes. Lo mismo es atribuible para quienes intervienen educativamente en dichos grupos sociales, o realizan las dos acciones simultáneamente, en tanto las metodologías de intervención exigen hoy cada vez mayor presencia de las y los trabajadores sociales en el espacio juvenil.

Una cuarta pista, que se sigue de la anterior, busca la superación de la rigidez mecanicista con que se ha mirado y se ha hablado de la juventud. En este sentido, planteamos la necesaria construcción de conceptos en torno al mundo juvenil, no en la pretensión de generar categorías totalizantes y universalizadoras, sino conceptos dinámicos y flexibles que se acerquen progresivamente a los sujetos de estudio: las y los jóvenes, las juventudes, las expresiones juveniles, los procesos de juvenilización. Este acercamiento progresivo utiliza la lógica de la tendencia al límite que nos enseña el cálculo algebraico: avanzar hacia el objetivo deseado (la realidad juvenil) siempre la mitad de lo que nos queda por recorrer. Vale decir, no es posible llegar a ella a cabalidad, pero siempre nos podremos acercar más y más. Su propio dinamismo y heterogeneidad es la que nos exige dinamismo en la actitud epistemológica y capacidad para mirar la diversidad juvenil. Si bien esta pista se amplía, al igual que las anteriores, a los diversos mundos sociales, la existencia de las juventudes y su reconocimiento, desafía a su concreción cotidiana por parte no sólo de los y las cientistas sociales, sino de las diversas sociedades en su conjunto.

A partir de las pistas antes señaladas, estamos en condiciones de plantear los ejes que podemos considerar en las lecturas de lo juvenil. Junto a las pistas presentadas existen ciertos ejes temáticos que el mundo diverso, plural y dinámico de las juventudes nos presentan hoy y que son vitales de tomar en cuenta cuando nos acercamos a conocer lo juvenil. Usamos lo juvenil para referirnos a las diversas producciones culturales y contraculturales que este grupo social realiza -en su diversidad y heterogeneidad ya mostradas-. Ello navega por los distintos espacios sociales en que este grupo social se despliega o inhibe en nuestras sociedades, vale decir, se expresa en la economía, en la religión, en las comunicaciones, en sus sexualidades, en sus intereses, etc. Lo juvenil es una producción, que se posiciona de acuerdo al contexto en que cada grupo de jóvenes se desenvuelve y en el tiempo histórico en que intentan resolver la tensión existencial que les plantea su sociedad: ser como lo desean o ser como se les impone. Esta pro- 
ducción de lo juvenil, nos pone de cara con la historicidad y facticidad que asumen las juventudes que hemos reconocido. Si bien entonces las juventudes no existen a priori y se van construyendo en un cierto espacio tiempo social, imaginario y real, ellas adquieren presencia no sólo desde el discurso de quien las habla, sino que sobre todo porque van ganando historicidad desde sus propias expresiones y muchas veces irrupciones en el espacio social.

Un primer eje es considerar que lo juvenil se constituye a partir de una cierto modo de vivir-sobrevivir a la tensión existencial que ya enunciamos. Se trata de un momento de la vida, que es independiente de la edad, y que se encuentra fuertemente condicionado por la clase social de pertenencia, el género que se posee, la cultura en la que se inscribe cada joven y sus grupos. Esta tensión existencial plantea una cierta lucha entre la oferta que la sociedad le presenta a las y los jóvenes para que cumplan con la expectativa que se tiene de integración al mercado, al conjunto de normas sociales y al rol de futuro adulto que les aguarda como tarea, y las construcciones más propias que ellos y ellas realizan respecto de la identidad que quieren vivir. Esta última se manifiesta en crítica social, desconfianza de los estilos adultos en la política y en las relaciones familiares y escolares, en provocación a las normas, en situarse al margen de lo que se espera que hagan (no inscripción electoral, no atención al mundo laboral, no adscribir a los modos culturales tradicionales, etc.), en resistir a las tendencias adultocéntricas que se dan en nuestras sociedades, entre otras formas de expresión.

A partir de lo anterior, surge un segundo eje a considerar en la producción de lo juvenil. Tiene relación con los distintos modos de agruparse en el espacio, que se caracterizan básicamente por la tendencia a lo colectivo con una cierta organicidad propia que les distingue y que las más de las veces no sigue los cánones tradicionales. ${ }^{5}$ Estas fórmulas organizativas de nuevo tipo les permiten dos aspectos que son centrales; por una parte, el grupo es el espacio privilegiado de socialización, especialmente en el caso de los hombres jóvenes que reciben un buen caudal informativo-normativo que alimenta sus iden-

5 No creemos que el instinto gregario por sí solo sirva para explicar la tendencia juvenil a la agrupación. Más bien consideramos que ella responde a condiciones sociohistóricas que en el caso de las y los jóvenes de sectores pobres se debe a la expulsión social de que son víctimas. No poseen espacios en sus casas y no existen condiciones ambientales-afectivas para permanecer en ellas por lo que la calle es su principal espacio de socialización. 
tidades de género; y por otra parte, el grupo es su familia afectiva, la comunidad en la que crean lazos que les mantienen y les aportan sentido a sus vidas y proyectos. En algunos casos el grupo juvenil se convierte en el vehículo de expresión social, ya sea por medio de lo contracultural, el deporte, lo político, algún servicio comunitario, etc.

El tercer eje a considerar en la construcción de lo juvenil en nuestro continente refiere a los nuevos modos de participar en la sociedad. Es común el cuestionamiento en que ha caído la actividad política en nuestras sociedades, dado principalmente el descrédito con que cuenta en tanto es percibida básicamente como instrumento de enriquecimiento y de acciones individuales que favorecen a minorías privilegiadas en contra de grandes grupos que sufren la marginación y la exclusión. Esta antipatía juvenil ante la política, en tanto modo tradicional de organización y participación de la sociedad, ha llevado a los distintos grupos de jóvenes a recrear nuevas formas de hacerse presente en los temas que les importan y que les son significativos. Dichas formas de expresión están reñidas con las formas tradicionales y se vuelcan directamente por la resolución efectiva de sus problemáticas inmediatas, acompañadas de un fuerte discurso moral y ético respecto de las conductas exigidas a las y los líderes juveniles y sociales. Las utopías juveniles están siendo presentadas de un modo diverso, propio de la especificidad que cada grupo despliega, ellas existen y más allá de los discursos adultocéntricos, se nutren de las actitudes de resistencia que diversos grupos juveniles van articulando (Goicovic, 2000).

Estos tres ejes presentados, en torno a la existencia de las juventudes en nuestro continente, componen en conjunto el proceso de construcción de identidades que hoy se dan entre las y los jóvenes. El proceso de resolución de la tensión existencial, los modos de agruparse-expresarse en el espacio y los estilos de participación en sus comunidades-sociedades les va imprimiendo las condiciones de posibilidad para tomar posiciones en sus ambientes íntimos y colectivos. Las y los jóvenes se van conformando en sujetos en la medida que resuelven su construcción identitaria, proceso infinito y desafiante, en que el vértigo es característica de estos tiempos (Silva, 1999).

Las juventudes cobran vida, se muestran, nos muestran sus diferentes estéticas y podemos asumir entonces una epísteme integradora, amplia y comprensiva de lo juvenil. La juventud niega existencia, porque ella encajona, cierra y mecaniza las miradas; rigidiza y superficializa el complejo entramado social que hemos denominado las 
¿Juventud o juventudes?

juventudes. Vamos por el camino de reconocer diferencias, aceptar diversidades, construir aceptaciones y de esa forma construimos miradas potenciadoras de lo juvenil.

Si logramos cambiar nuestras miradas, por cierto que estaremos en condiciones de acercarnos más a los grupos juveniles y recoger desde ellos y ellas sus expresiones propias de sueños, esperanzas, conflictos, temores, propuestas. Este es un desafío para nuestro próximo tiempo, reconstruir categorías y epistemologías que nos permitan mirar y remirar a las juventudes de nuestro continente con nuevos ojos, oírles con nuevos oídos, tocarles con nuevas manos, degustarles con otras bocas y sentirles con nuevos olfatos...

En este proceso de lograr cercanías y facilitar sus expresiones propias, lo intergeneracional como posibilidad de encuentro y de reconstrucción de puentes rotos es una exigencia de cara al nuevo tiempo. Validar el intercambio de experiencias, los aprendizajes mutuos y por ende la superación de las barreras que la matriz adultocéntrica nos impone, le otorga una fuerza política importante a la presencia de las juventudes en nuestras sociedades.

SANTIAGO, ABRIL DEL 2000

\section{BIBLIOGRAFÍA}

Bourdieu, P. (1990): La juventud no es más que una palabra. México: Grijalbo/CNCA.

DUARTE, K. (1994): Juventud popular. El rollo entre ser lo que queremos o ser lo que nos imponen. Santiago: LOM Ediciones. (1996): «Ejes juveniles de lectura, para desenmascarar las bestias y anunciar los sueños». Revista Pasos Nº. San José de Costa Rica: DEI.

KUASÑOSKY, S. y D. SzULIK (1995): «Desde los márgenes de la juventud». En Mario Margulis (editor): La juventud es más que una palabra. Ensayos sobre cultura y juventud. Buenos Aires: Editorial Biblos.

GALLARDO, H. (1998): El fundamento social de la esperanza. Quito: Escuela de Formación de Laicos y Laicas, Vicaría Sur de Quito, Ecuador.

GoICOVIC, I. (2000): «Del control social a la política social. La con- 
flictiva relación entre los jóvenes populares y el Estado en la historia de Chile». Última Década Nº12. Viña del Mar: Ediciones CIDPA.

KuHN, T. (1980): La estructura de las revoluciones científicas. México: Fondo de Cultura Económica.

MuÑoz, V. (1999): «El tratamiento de la juventud desde una perspectiva histórica. Aspectos conceptuales». Inédito.

Silva, J. C. (1999): Noventas. De maratones, vértigo y sospecha. De vuelta a casa... para salir de nuevo. Derechos Juveniles V Región. Viña del Mar: Ediciones CIDPA. 